\title{
Investigation of environment waste resultant from incorrect excretion of stock car rubbers and determination quantity, a current situation and fate of them (a case study: Ahvaz, Iran)
}

\author{
Mohsen Eslami ${ }^{1}$, Farzaneh Fakeri Raof ${ }^{2,}{ }^{*}$, Mohammad Jorjor Zadeh ${ }^{3}$
}

\footnotetext{
${ }_{1}^{1}$ Master's Degree student in environmental pollution, Islamic Azad University, Khuzestan, Iran

$2 \mathrm{PhD}$ degree in environmental Science. Science committee of Islamic Azad University, Khuzestan, Iran

${ }^{3}$ Master's degree in civil engineering, Science committee of Islamic Azad University, Ahvaz, Iran
}

\begin{abstract}
A healthy environment is an absolute necessity for the well-being of all governments' policy. The population on the earth is expanding rapidly which goes hand in hand in the degradation of the environment at large measures. The human's appetites for needs are disarranging the environments natural equilibrium. Growth of automobile industry in the world due to dignity to the parallel with increasing the production of rubber in the world. So increasing the disposal of worn tires is one of the world's great challenges. Annually, large amount of rubbers in the world is prepared. The rubber used in normal conditions can't be easily decomposed and make environmental pollution. This study was performed in Ahvaz metropolitan. The information in this study was achieved by questionnaire were asked of 40 shops, who was activated in the tire field. After this research revealed turned out about 300 shops were activated in the field of tires at the time of this study(2014), Also revealed 2700 tire rings out of cycle per day in Ahvaz in this study (68\%) questionnaire, believed that the tires after release from the workshop are collected by badger. (22\%) believed that collected by municipal. Also (7\%) of questionnaire believed that they didn't have any information about the release tires. At least only (3\%) believed that himself collect damaged tires in their workshops. The application of the tire after collection in the idea of responded following: 15 person of questionnaire believe the tires sold after release from the workshop. 9 person said tires left in the wild. 8 persons believed that tires buried in a special place, Also 6 persons of questionnaire believed that tires are getting burned. At the end 2 persons of questionnaire believed that they don't know the fate of tires. At least some of the environmental hazards caused by incorrect tire were buried as were recommendation to improve.
\end{abstract}

Keywords: Environmental hazard, used tires, Analysis, Pollution, burial incorrect, Ahvaz 


\section{Introduction}

E nvironmental issues are harmful effects of human activity on the environment. Around 70 percent of disasters are now climate related - up from around 50 percent from two decades ago. These disasters take a heavier human toll and come with a higher price tag. In the last decade, 2.4 billion people were affected by climate related disasters, compared to 1.7 billion in the previous decade. The cost of responding to disasters has risen tenfold between 1992 and 2008. Destructive sudden heavy rains, intense tropical storms, repeated flooding and droughts are likely to increase, as will the vulnerability of local communities in the absence of strong concerted action." (OCHA) "Climate change is not just a distant future threat. It is the main driver behind rising humanitarian needs and we are seeing its impact. The number of people affected and the damages inflicted by extreme weather has been unprecedented. While rubber mulch is often touted as being a permanent mulch material, rubber is like any other organic material in that it does break down when subjected to sunlight, bacteria and fungi. As it decomposes, the chemicals in the rubber leach into the soil and nearby water sources. Many of these chemicals, as well as heavy metals, are dangerous to plants, soil and aquatic systems. Ornamentals and vegetables mulched with rubber can accumulate high levels of metals used in rubber tires, such as zinc. These metals can build up in plant roots, leaves, or fruit, depending on the plant, and this can lead to plant death. Removing the mulch only solves part of the problem because although the source of the problem is gone, the metals that have leached into the soil are still being taken up by plant roots."Tire recycling or rubber recycling is the process of recycling vehicles' tires (British English tires) that are no longer suitable for use on vehicles due to wear or irreparable damage (such as punctures). These tires are among the largest and most problematic sources of waste, due to the large volume produced, their durability, and the fact they contain a number of components that are ecologically problematic. It is estimated that 259 million tires are discarded annually (data is for the 1980's and 1990's) [1] the same characteristics that make waste tires problematic, their cheap availability, bulk, and resilience, also make them attractive targets for recycling. Nonetheless more than half of used tires are simply burned for their fuel value [2] even in advanced countries like Germany, 55\% are estimated to be burnt for fuel. Approximately, one tire is discarded per person per year. Tires are also often recycled for use on basketball courts and new shoe products. However, material recovered from waste tires, known as "crumb," is generally only a cheap "filler" material and is rarely used in high volumes.[3] A large amount of rubbers in the world is prepared. For instance 3.6 million ton tires produced annually in the US. Emptying and disposing the rubber content in the environment is not possible and these materials should be recycled. Tire can be used to improve some properties of the concrete. Adding rubber to concrete resulting in improved mechanical and dynamic features are concrete. for example energy absorption, better ductility, better resistance to cracking.[4] With an overview to statics production of rubber production in the country and also the tire imports to the conclusion that 300 hundred thousand tons of tire are worn in the country has caused environmental pollution and the loss of biological life. Recycled rubber is completely different principal with is happing in our country now. In our country are not favorable growth worn tire recycling industry and this industry only in limited causes, like recap tires, reclaimed, and production of rubber powder. At Iran 8 million customers are rubber ring annually. That they lead to environment after destroyed in a different ways and contaminated their environment. Tire recycled and the prevention of environmental pollution and can help to meet the basic need of the industry.[5]Including significant losses every year due to the number of cars on the roads is produced rubber is worn out car. Smooth wheel is dangerous for the public and private vehicles and should not be used. On the other hand waste recovery 
such as those that are effective in preventing the waste of resources. Waste reduction, waste separation and recovery of the damages that they cause the return to the production cycle again. In addition, the product, the raw material for many industries such as flooring, all kinds of reinforcement and color replacement, asphalt, concrete and as the primary fuel for the furnace and raw material is rubber, etc. Has application. And many applications inside and outside the country. Meanwhile, rubber recycling industry is highly regarded in the world because of the value of goods produced, also many large companies are professional on this industry and investment. Life tire recycling industry is low in Iran. Iran is a very broad field of activity for new artisans. Due to the properties of rubber and rubber powders are many significant applications. That these applications are being developed in our country. Unfortunately there are no accurate statistics on the amounts of waste tires the global value of scrap tires more than ten million tons per year is estimated.

\subsection{Stockpile and legal dumping}

Tire stockpiles create a great health and safety risk. Tire fires can occur easily, burning for months, creating substantial pollution in the air and ground. Recycling helps to reduce the number of tires in storage. An additional health risk, tire piles provide harborage for vermin and a breeding ground for mosquitoes that may carry diseases. Illegal dumping of scrap tires pollutes ravines, woods, deserts, and empty lots; which has led many states to pass scrap tire regulations requiring proper management. Tire amnesty day events, in which community members can deposit a limited number of waste tires free of charge, can be funded by state scrap tire programs, helping decrease illegal dumping and improper storage of scrap tires. Unfortunately, tire storage and recycling are sometimes linked with illegal activities and lack of environmental awareness [7]

\subsection{Landfill disposal}

Tires are not desired at landfills, due to their large volumes and $75 \%$ void space, which quickly consumes valuable space.[8] Tires can trap methane gases, causing them to become buoyant, or bubble to the surface. This 'bubbling' effect can damage landfill liners that have been installed to help keep landfill contaminants from polluting local surface and ground water.[9]Shredded tires are now being used in landfills, replacing other construction materials, for a lightweight backfill in gas venting systems, leachate collection systems, and operational liners. Shredded tire material may also be used to cap, close, or daily cover landfill sites.[10] Scrap tires as a backfill and cover material are also more cost-effective, since tires can be shredded on-site instead of hauling in other fill materials. Tires can be reused in many ways, although again, most used tires are burnt for their fuel value.

\section{Research carried out so far}

\subsection{Research carried out in Iran}

With an overview of the country tire manufactures an tire imports to the conclusion that approximately 300 thousand tons of old tires in the country has caused environmental pollution and loss of biological life. recycling industrial tires only to activities and production of rubber powder and coating industry limited. In Iran, about 8 million ring used tires annually. The scrap tires can help to meet the needs of the industry the reuse them prevent environmental contamination [11]

The other article was submitted for environmental protection. At this article was reuse of waste tires and worn tires. Also checked out the feasibility used of rubber fibber. If unpractical buried the fibber in the rubber can cause environmental pollution. Also this materials have many persistence in soil. If the fibber in the powder reuse of worn out tires, the solution on this waste in construction project can be found and also improve the mechanical behavior causes. Katebi and his colleagues have identified in his study add polymeric fibers increase the shear strength and ductility of the sample. At least at this article showed instead of sand in construction project can be waste rubber 
industry that modified polymeric materials. [12]

In another study, researchers concluded that increased compressive strength of concrete containing rubber, if rubber powder in concrete for added control. In this study, in foam rubber and silica and Nano silica were mixed. Increase the strength of concrete at 28 days was higher than 7 days. Also the strength of concrete containing rubber was mixed with foam silica was better than concrete contain rubber was mixed wide Nano silica. [13]

\subsection{Study abroad}

Since 1960, decade around the world especially the developed containers using recycled rubber powder widely used in construction to reduce environmental pollution. Lopersi and his colleagues at this article considered that the possibility of using recycled rubber powder in asphalt for roads and highways. In this article Lopersi and his colleagues revealed using recycled rubber powder in asphalt increased friction between tires and asphalt. In addition when the car breaks suddenly to prevent slipping. [14]

Concrete properties of rubber powder was examined in another article and showed added to the $14 \%$ specified rubber powder does not causes changes in the properties of concrete and use rubber powder up to $14 \%$ is permitted in concrete.[15]

A large reduction in the compressive strength and increase ductility waste the result of the increase rubber powder to concrete. This article will review at 2010 by El-Gamal and his colleagues. [16]

Checked out an article self-compacting concrete was recycled scrap tires. At this article, environmental survey was conducted by the disposal of tires in nature. Also concluded that self-compacting technology helps to the rubber link. [17]

\section{The study area}

This research was carried out in Ahvaz, capital city of the province of Khuzestan located in the southwest of Iran, with an area of $238.8 \mathrm{~km} 2$. It consist of eight wards and has families from different socioeconomic backgrounds. Ahvaz has a population of 1.115.133. This municipality is characterize by its industrial activity. [18]Ahvaz is located 18 meters above sea level. According to the latest official statistics $32 \%$ of people are in the metropolitan. $35 \%$ of people lives in the suburbs. Ahvaz is the second city in terms of marginalizing. $51 \%$ of Iranian oil is produced in Ahvaz. There are some of the biggest factories in Ahvaz. In terms of population, Ahvaz is seventh in Iran. Also Ahvaz is an important transit because by way of land, air, rail land. Other parts of the country is connected to the main ports in Iran, like Abadan, Khoramshahr, Mahshahr. The most important environmental problem depended to population growth. 


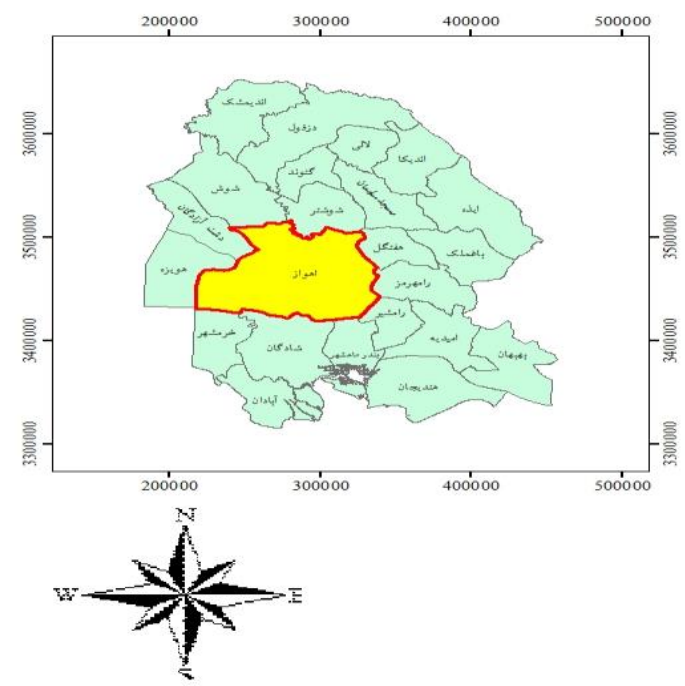

4. Methodology

4.1 The method of collection waste tires in Ahvaz

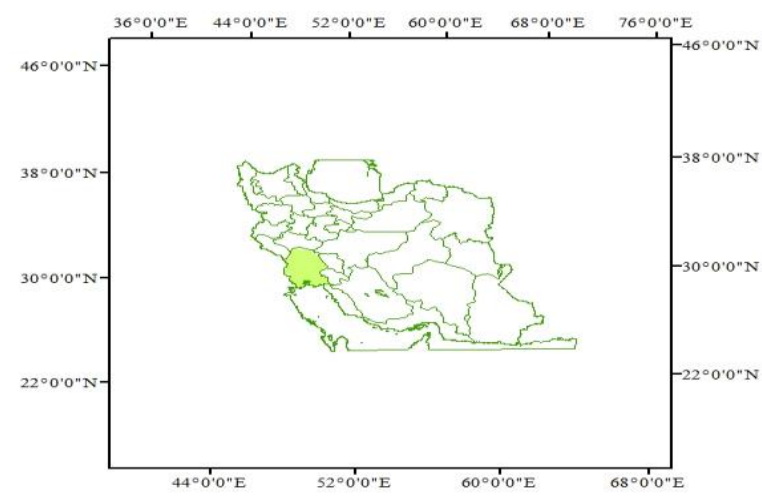

Diagram (4-1) is showed the method of collecting waste tires in Ahvaz. This graph is based on the number of respondents provided.

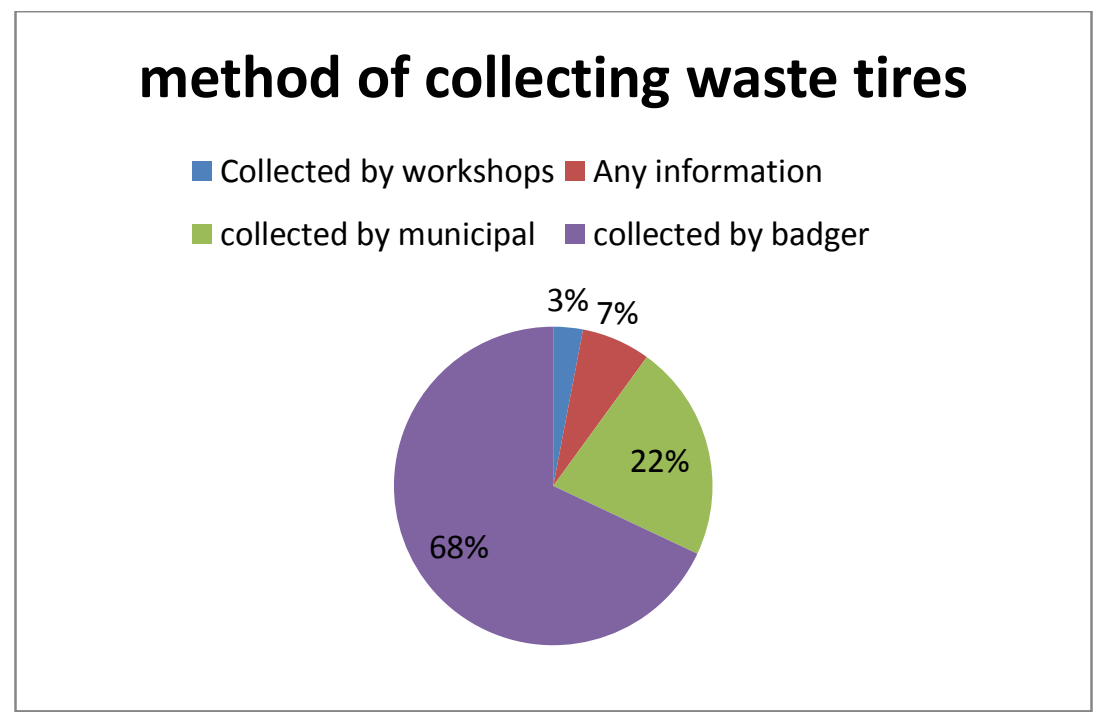

Diagram (4-1) the method of collecting waste tires in Ahvaz

Diagram (4-2) is showed the fate of collecting waste tires in Ahvaz. This graph is based on the number of respondents provided. 


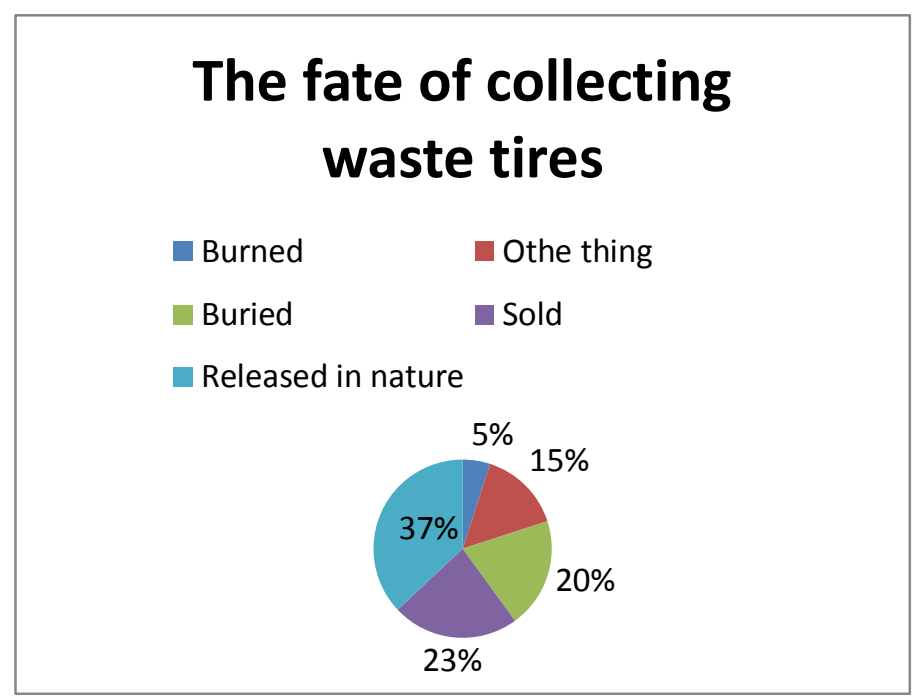

Diagram (4-2) the fate of collecting waste tires in Ahvaz

4.3 Determine the quantity of waste tire

There is no any information about the quantity of waste tire in Ahvaz and so far research has been done on this area, so it was don decided by the rubber association of Ahvaz interview. After this interview as found
300 shop and workshop received the permitted for working from this center. So 40 centers randomly were asked about information on tires in Ahvaz. According to respondents, the quantity of waste tire as showed in diagram (4-3) The quantity of waste tire showed in diagram (4-3 )

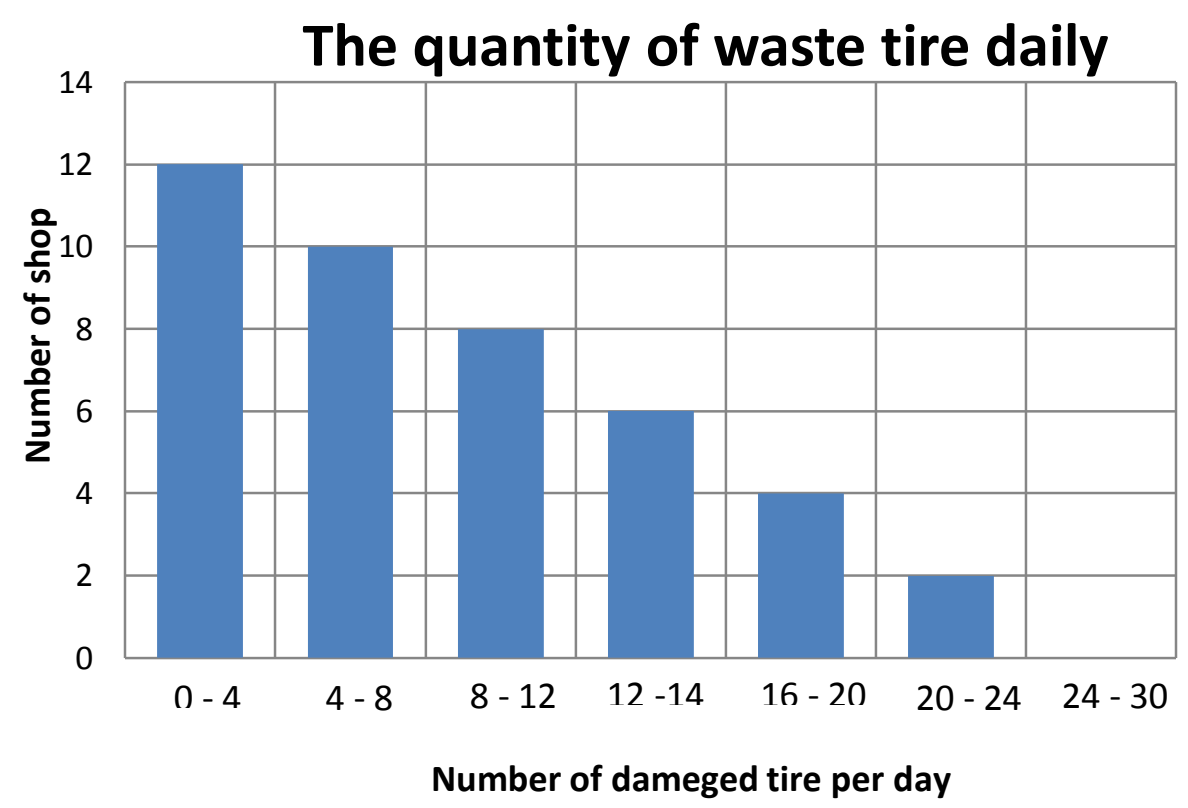

\section{Conclusion}

After analyzing the result of the questionnaire(4-1) revealed the following: 27 persons of questionnaire $(68 \%)$ whom working in the field of tirs, believe that the tires after release from workshop are collected by badger.9 persons of questionnaire who that worked in the field of tires(22\%) believe that the tires after release from the workshop are collected by municipal. Also 3person of questionnaire $(7 \%)$ believe that they haven't 
any information about the release tires. At least only one of the questionnaire (3\%) believe that he collects damaged tires in his workshop himself.

The application of the tire after collection in the idea of responded following (Diagram42):15 person of questionnaire whom works in the field of tires (37\%) believe that the tires will be sold after release from the workshop. 9 persons $(23 \%)$ said tires will get discarded in the wild after collecting from workshop. 8 person $(20 \%)$ believe that tires are getting buried in a special place after collecting from workshop. Also 6 persons of questionnaire $(15 \%)$ believe that tires are getting burned. At the end, 2 persons of questionnaire (5\%) believe that they don't know the fate of tires. Totally according to the information that obtained from the questionnaire determined at least $56 \%$ of waste tires in Ahvaz abandoned in nature or non-systematic buried or burned. By result of diagram4-3 obtained 2700 rubber rings out of cycle per day in Ahvaz. With regard to the points mentioned however damaged tires caused to air pollution, sol pollution or groundwater pollution. According to the international and external investigation, waste rubber powder can be substituted with different percentage of fillers material used in the construction industry. Also add powder rubber in many cases concrete with controlled levels without altering the properties of concrete is possible in many cases. Adding the waste rubber powder in the road construction industry to improve the properties of the asphalt. This material prevent cracking of asphalt and causes more friction. The recovery process and the optimum use of recourse and attitude to environmental protection seriously what's the national attention at application development recovery of scrap tires are seriously thinking of 70 years ago was established the countries of west. Parallel to the foundation and development of the tire industry. This days the idea of recycling scrap tires for various causes over $60 \%$ savings in the use of raw materials were. This recovery will be different use the coating for powder and prepared reclaimed, recycled and reused as a raw material in the manufacturing of these material is rubber. Recycled rubber, plastic, paper and etc. in developing countries do not have the technology and raw materials is an important issue and not to pay attention. Waste rubber from used tire because of the inseparability of nature causing damaged to the environment. In the overview the destruction of used rubbers cause the destruction of expensive resources. These expensive materials are raw materials used in the manufacture of rubber, so recycling of used tires seem necessary. Researchers to recycle rubber tire used in building materials has attracted to some rubber properties such as low density and high flexibility. The features mentioned above can improve some properties such as density and plasticity of concrete. Waste recovery in some cases are very effective in preventing the waste of recourses. Waste reduction and waste separation causes to recovery of some valuable material to reuse in industry. Recovery of rubber waste can be used in many ways, manufacture of paints industry, the main fuel furnaces and raw material rubber industry. Waste reduction, waste separation and recovery of the damages that they cause the return to the production cycle again. In addition, the product, the raw material for many industries such as flooring, all kinds of reinforcement and color replacement, asphalt, concrete and as the primary fuel for the furnace and raw material is rubber, etc. Has application. and many applications inside and outside the country .Meanwhile, rubber recycling industry is highly regarded in the world because of the value of goods produced, also many large companies are professional on this industry and investment. Life tire recycling industry is low in Iran. Iran is a very broad field of activity for new artisans. Due to the properties of rubber and rubber powders are many significant applications. That these applications are being developed in our country. Unfortunately there are no accurate statistics on the amounts of waste tires the global value of scrap tires more than ten million tons per year is estimated. Due to their heavy metal and other pollutant content, tires pose a risk for the (leaching) of toxins into the 
groundwater when placed in wet soils. Research has shown that very little leaching occurs when shredded tires are used as light fill material; however, limitations have been put on use of this material; each site should be individually assessed determining if this product is appropriate for given conditions [19] Eco toxicity may be a problem. Studies show that zinc, heavy metals, a host of vulcanization and rubber chemicals leach into water from tires. Shredded tire pieces leach much more, creating a bigger concern, due to the increased surface area on the shredded pieces. Many organisms are sensitive, and without dilution, contaminated tire water has been shown to kill some organism [20]

\section{Suggestion}

- Facilities of the municipality to collect and transfer to the rubber recycling plants.

- Management practices to determine the politicized and implementation of recycling scrap tires.

- Given the encouraging expert for recycling scrap tires and exporter's powder, rubber and products.

- Supporting rubber recycling industry

- Detailed studies for the use of recycled rubber in the different industry.

- Motivate and encourage manufactures to use rubber powder familiar with its problems.

- Financial assistance from the found from Department of the environment to compensation for transportation costs, safety and similar cases.

\section{REFERENCES}

Bandyopadhyay, S.; Agrawal, S.L.; Ameta, R.; Dasgupta, S.; Mukhopadhyay, R.; Deuri, A.S.; Ameta, Suresh C.; Ameta, Rakshit (2008). "An overview of rubber recycling". Progress in Rubber, Plastics and Recycling Technology 24: 73-112.

Myhre, Marvin; MacKillop, Duncan A (2002). "Rubber recycling". Rubber Chemistry and $\begin{array}{llll}\text { Technology } & 75 & \text { (3): } \quad 429-474 .\end{array}$ doi:10.5254/1.3547678.

Desmond Threadingham, Werner Obrecht, Wolfgang Wieder, Gerhard Wachholz and Rüdiger Engehausen "Rubber, 3. Synthetic Rubbers, Introduction and Overview" in Ullmann's Encyclopedia of Industrial Chemistry, 2011

Gerami, m. Bashiri, E,. Thaghdisi, M.H,. Siahpolo, N,.(2011). Some features of concrete containing rubber powder, the first national conference of the concrete industry.

Functional and economic advantage of using rubber powder. Journal of rubber industry, paper recycling. No 59. p 189

Mostophinezhad,D. Mohammadpour, B. Aminzade,H. Taghizade,A.(1994). Second international conference on concrete and development.

http://www.bbc.co.uk/news/uk-englanddevon-17195524

Agrawal, S.L.; Ameta, R.; Dasgupta, S.; Mukhopadhyay, R.; Deuri, A.S.; Ameta, Suresh C.; Ameta, Rakshit (2008). "An overview of rubber recycling". Progress in Rubber, Plastics and Recycling Technology 24: $73-112$

In a 2003 report cited by the U.S. EPA, it is stated that markets ("both recycling and beneficial use") existed for $80.4 \%$ of scrap tires, about 233 million tires per year. Assuming $22.5 \mathrm{lbs}$ per tire, the 2003 report predicts a total weight of about 2.62 million tons from tires

$22.5 \mathrm{lb}$ working figure retrieved on 20 February 2010 from: http://www.rma.org/scrap_tires/scrap_tire_ markets/scrap_tire_characteristics/

Mokhtari mehr, M, (2004). the use of recycled rubber and rubber powder at different part of rubber. Iran rubber journal. Special recycled rubber, No42, p150

Katebi,H. Ghazavi, A. Alavi, A. (2008) Resources of waste tire and worn tires to conservation of environmental protection. 
Sohrabi, M.R, Karbalaei, M(2011),; An Experimental Study on Compressive Strength of Concert Containing Crumb Rubber:, International Journal of Civil \& Environmental Engineering IJCEE-IJENS Vol.: 11 No: 03

Lo Persti.D . Notimgham (2013) Transportation Engineering Center.Univerciry of Notinghom.uk. Construction and Building Materials 49.863-881

Pelisser,F. Zavarise,N Tiago Arene Longo,Adrino Bernardin.A,M(2011). Journal of cleaner production 19757-76

El-gammal,A.A. k. Abdel-(2010)" Investigation of rubber prouder for usage of construction" Gawad;Y.El.Sherbini,and A ,(Shallabi),"Compressive

Eldin, N.N., and Senouci A. B., Rubber,(1993)Tire particles as Concrete Aggregate, Journal of Materials in Civil Engineering . 5 (4). 478-496.

Monavari, s.m. Omrani.Gh,A. KarbasitA. Fakheri Raof.F"(2011) the effect of socioeconomic parameters on household solid-wast generation composition in developing countries (a case study: Ahvaz, Iran)".Springer Sience

Liu,H., Mead, J., Stacker, R. Chelsea Center For Recycling And Economic Development. (1998). Environmental Impacts Of Recycling Rubber In Light Fill Applications: Summary \& Evaluation Of Existing Literature University of Massachusetts

Toxicity study http://www.ardeacon.com/pdf/Assessment Environmental Toxicity Report 